\title{
Emotional distress in junior house officers
}

\author{
JENNY FIRTH-COZENS
}

\begin{abstract}
In a study of 170 junior house officers who were followed up from their fourth year in medical school mean levels of stress were higher than in other reported occupational groups, and the estimated prevalence of emotional disturbance was $50 \%$, with $28 \%$ of the subjects showing evidence of depression. Nearly a fifth of the subjects reported occasional or frequent bouts of heavy drinking, a quarter took drugs for physical illness, and a few took drugs for recreation. Those who were emotionally distressed at the initial study and the follow up were more empathetic and more self critical than those who had low levels of stress on both occasions. Overwork was the most stressful aspect of their jobs, though the number of hours worked was not related to stress levels, unlike diet and sleep. The more stressed they were the more unfavourably they viewed aspects of their jobs.

The incidence of distress is unacceptably high in junior house officers, and both they and the hospitals need to deal with the causes of the distress.
\end{abstract}

\section{Introduction}

Medical practitioners seem to suffer unacceptably high levels of psychiatric illness, ${ }^{1}$ mainly depression and suicide, ${ }^{2}$ dependence on alcohol, ${ }^{3}$ and drug abuse. ${ }^{4}$ Although these problems may develop over many years, the preregistration, or junior house officer, year has been singled out by North American authors as the time of most experienced distress, ${ }^{5-8}$ with reported rates for depression of at least $33 \% .^{29}$

MRC/ESRC Social and Applied Psychology Unit, University of Sheffield, Sheffield S10 2TN

JENNY FIRTH-COZENS, BSC, MSC, clinical psychologist
The longitudinal study of stress and coping in British medical practitioners that $I$ am carrying out was begun in their fourth year of medical school ${ }^{10}$ and was encouraged by the reaction of staff to the suicides of two junior house officers. In this first follow up of the subjects, who are now in the first postgraduate year, I investigated (i) the incidence of depression and of alcohol and drug use to make comparisons with previous studies ${ }^{113}$ and (ii) the incidence of general stress to compare this group with other occupational groups.

To find the possible causes of emotional distress in these subjects I looked at the role of sleep, diet, and aspects of work in relation to stress and whether men and women differed in their reported experiences. In addition, I was able to investigate whether those who were highly stressed as undergraduates continued to be so in the first postgraduate year and whether those who had had few symptoms previously remained that way despite the difficulties encountered. I also considered whether personality or cognitive factors might be concerned in the maintenance of high or low stress scores. It was therefore predicted that lower empathy and lower self criticism, together with the ability to blame outside forces rather than oneself for things that go wrong,${ }^{14}$ may protect the individual from job stress in a medical environment.

\section{Method}

\section{QUESTIONNAIRE}

The questionnaire contained questions on personal history, stress, depression, personality, and job related factors. The sections that concern this paper are the General Health Questionnaire, the Symptom Check List Depression Scale, personality factors, and work factors.

General Health Questionnaire $(G H Q 30)$-The 30 item version of this scale has been used to estimate minor psychiatric morbidity in the community ${ }^{15}$ and has also been used in the workplace. ${ }^{16}$ Means were assessed using the Likert method, in which each item has a range of zero to three (maximum score 90), and prevalence estimations were assessed by using the General Health Questionnaire, in which each item is scored zero or one (maximum score of 30.) Using this method a score of four or more indicates that the 
person is likely to be regarded as a "case" on psychiatric assessment. The GHQ 30 contains the 12 item version (GHQ 12) that was used in the initial assessment of these subjects, ${ }^{10}$ where a score of three or more indicates caseness. For convenience, the GHQ 30 scores are referred to as "stress scores."

Symptom Check List Depression Scale ${ }^{17}$-This 10 item scale is part of a validated self report inventory of symptoms that is designed to measure several dimensions of psychopathology. Each item is scored zero to four, and the overall item mean for the scale was calculated.

Personality-Empathy was measured using the Emotion and Empathy Scales ${ }^{18}$ which include several items rated on seven point scales, giving an overall mean. Attributions for negative events were assessed using items from a scale that was designed to measure perceived responsibility. ${ }^{19}$ Self criticism was measured using the scale that was designed and validated by Blatt. $^{20}$

Subjects were asked to rate their drinking habits on a five point scale (from "never" to "a lot often") to assess alcohol and drug intake and were asked to say whether drugs were used for illness, tension, depression, sleep, or recreation.

Work-Subjects were asked questions related to their job concerning sleep, number of hours worked, diet, and job characteristics, which were rated on a five point scale producing an overall mean. They were also asked to rate on a four point scale (from "not stressful" to "extremely stressful") a list of events reported by doctors to cause problems in a pilot study and published papers.

\section{SAMPLE AND PROCEDURE}

The 238 fourth year medical students from the first study ${ }^{10}$ who graduated in 1985 were sent questionnaires in March of their preregistration year. In addition, 50 preregistration doctors who were resident around Sheffield and who had not returned questionnaires in the first study were sent a shorter version of the questionnaire. They were sent $£ 5$ on receipt of questionnaires.

Pearson's correlations were used to study the relations between stress or depression and various aspects of work. Analyses of variance and $t$ tests were used to look at differences between populations.

\section{Results}

Completed questionnaires were returned by $170(72 \%)$ of the 238 subjects in the follow up sample. Twenty five of the 50 additional questionnaires sent out were returned but showed a mean GHQ 30 score of $31 \cdot 80$, which was significantly above the main sample mean (SD) of $27 \cdot 18(10 \cdot 85)(\mathrm{F}=5 \cdot 46$, $\mathrm{p}<0.05)$. The depression means were also higher $(F=4 \cdot 10, p<0.05)$, with five $(20 \%)$ of 25 in the extra group reporting suicidal thoughts compared with $10(6 \%)$ subjects in the main sample. Because of these differences reported analyses are limited to the 170 respondents who had taken part in the initial study.and who graduated in 1985 .

With the method of scoring and validity data for the recommended cutoff of three out of four ${ }^{21}$ from the General Health Questionnaire, the estimated prevalence of emotional disturbance in this group was $50 \%$. Extracting the appropriate items from the GHQ 30 provided a mean for the GHQ 12 of 11.91 (range 3-25) compared with the mean in the initial study of 11.66 . There was a significant relation between scores in the initial and the follow up studies $(r=0.36, p<0.000)$.

The mean item depression score was $1 \cdot 14$. This compares with 1.61 in Lloyd and Gartrell's study of medical students ${ }^{22}$ and with 1.02 in a study of students in general. ${ }^{23}$ There are no reported norms for the United Kingdom, but a group of professional and managerial patients who had a psychiatric diagnosis of depression on the Present State Examination showed a mean (SD) score on the Symptom Check List of $2 \cdot 17(0 \cdot 69) .{ }^{24}$ With a cutoff of one standard deviation below this mean $(1.5) 45(28 \%)$ subjects in the follow up study scored at or above this measure of psychiatric morbidity.

Table I gives the mean scores for stressful aspects of work and their correlations with GHQ 30 and depression scores. Subjects reported "overwork" as being the most stressful aspect of their jobs, followed by "talking to distressed relatives," "effects on personal life," and "serious treatment failures." Stress and depression were highly correlated with "relations with consultants," "effects on personal life," "overwork," and "making decisions."

Mean scores on the job characteristics questionnaire were significantly negatively correlated with stress $(-0.60, \mathrm{p}<0.000)$, indicating that the subjects who were feeling more stressed saw aspects of their job as less favourable. For example, the more stressed they were the less able they were to discuss problems about work with senior colleagues $(r=0.40)$, the less they knew what was expected of them $(r=0.38)$, the more they felt overwhelmed by the responsibility $(r=0.45)$, and the less they saw themselves as continuing to practise medicine $(r=0 \cdot 26)$. Twenty three house officers (14\%) expressed strong (scores of 6 or 7) dissatisfaction with their choice of career; 66 (39\%) expressed strong (scores of 1 or 2) satisfaction. Seventy eight $(46 \%)$ agreed and $26(15 \%)$ disagreed with the statement: "A counselling service should be provided for medical staff," and the rest had no opinion.

TABLE I-Mean perceived stressfulness and its relation to General Health Questionnaire (GHQ) and depression (Symptom Check List) scores for aspects of work

\begin{tabular}{lcll}
\hline & & \multicolumn{2}{c}{ Relation with: } \\
\cline { 3 - 4 } Aspect of job & $\begin{array}{c}\text { Mean perceived } \\
\text { stressfulness }\end{array}$ & GHQ & SCL 90 \\
\hline Relations with consultants & $1 \cdot 61$ & $0 \cdot 45^{\star \star \star}$ & $0 \cdot 50^{\star \star \star}$ \\
Relations with registrars & $1 \cdot 27$ & $0 \cdot 25^{\star \star \star}$ & $0 \cdot 18^{\star}$ \\
Relations with senior house officers & $1 \cdot 16$ & $0 \cdot 26^{\star \star}$ & $0 \cdot 23^{\star \star}$ \\
Relations with nursing staff & $1 \cdot 25$ & $0 \cdot 19^{\star \star}$ & $0 \cdot 18^{\star}$ \\
Dealing with death & $1 \cdot 70$ & $0 \cdot 10$ & $0 \cdot 19^{\star \star}$ \\
Talking to distressed relatives & $2 \cdot 25$ & $0 \cdot 13$ & $0 \cdot 18^{\star}$ \\
Making decisions & $1 \cdot 83$ & $0 \cdot 35^{\star \star \star}$ & $0 \cdot 32^{\star \star \star}$ \\
Effects on your personal life & $2 \cdot 19$ & $0 \cdot 43^{\star \star \star}$ & $0 \cdot 42^{\star \star \star}$ \\
Overwork & $2 \cdot 47$ & $0 \cdot 37^{\star \star \star}$ & $0 \cdot 41^{\star \star \star}$ \\
Being underutilised & $1 \cdot 14$ & $0 \cdot 03$ & $0 \cdot 12$ \\
Having too few skills & $1 \cdot 86$ & $0 \cdot 21^{\star \star}$ & $0 \cdot 28^{\star \star}$ \\
Inflicting pain & $1 \cdot 67$ & $0 \cdot 06$ & $0 \cdot 20^{\star \star}$ \\
Financial problems & $1 \cdot 45$ & $0 \cdot 05$ & $0 \cdot 11$ \\
Serious treatment failures & $2 \cdot 18$ & $0 \cdot 05$ & $0 \cdot 23^{\star \star}$ \\
\hline
\end{tabular}

${ }^{\star} \mathrm{p}<0.05 ;{ }^{\star \star} \mathrm{p}<0.01 ;{ }^{\star \star} \mathrm{p}<0.001$

The mean number of hours worked or on call was 90.6 duriıg that week. There was no relation between stress or depression and the number of hours worked in a week, nor the number of beds for which subjects were responsible. Significant correlations existed between depression and having problems adjusting to sleep patterns $(0.32, \mathrm{p}<0.001)$, as well as having an inadequate diet over the previous week $(0 \cdot 21, \mathrm{p}=<0.01)$. Stress scores were also correlated with diet $(0 \cdot 15, \mathrm{p}<0.05)$, problems with sleep patterns $(0 \cdot 26$, $p<0.001)$, and the number of hours slept in the past 48 hours $(r=0.15$, $\mathrm{p}<0.05$ ).

Subjects in teaching hospitals were significantly more stressed $(F=9 \cdot 84$, $\mathrm{df}=1, \mathrm{p}<0.01)$ and more depressed $(\mathrm{F}=4.17 \mathrm{df}=1, \mathrm{p}<0.05)$ than those in non-teaching hospitals.

Though there was no relation between reported drinking habits and stress or depression, $32(19 \%)$ subjects scored in the top two categories of the scale and nine $(5 \%)$ in the top category. There was a correlation of $0.37(p<0.001)$ between the initial and the follow up studies in drinking habits. No student rated drug use in the top two categories: $44(25.9 \%)$ were taking drugs for physical illness, two $(1 \cdot 2 \%)$ for sleep, one $(0.6 \%)$ for depression, four $(2 \cdot 4 \%)$ for anxiety, and $12(7 \cdot 1 \%)$ for recreation.

Two groups were selected for being above threshold $(>2)$ on the GHQ 12 on both occasions $(38,22 \cdot 4 \%)$ or below on both occasions $(63,37 \cdot 1 \%)$. The first group was significantly more disillusioned with their career choice at the initial study $(t=2.36, \mathrm{p}<0.05)$ and at follow up $(t=3.64, \mathrm{p}<0.001)$, scored higher on empathy at the first $(t=2 \cdot 16, \mathrm{p}<0.05)$ and at the second $(t=3 \cdot 36$, $\mathrm{p}<0.001)$, were more internal in their attributions at the second $(t=4.02$, $\mathrm{p}<0.001)$, and were more self critical at the first $(t=5.96, \mathrm{p}<0.000)$ and at the second $(t=8.06, \mathrm{p}<0.000)$ (table II).

Women were not significantly more stressed than men $(F=1.97)$ and showed no greater proportion of possible cases $\left(\chi^{2}<1\right)$, but a mean score of 1.29 compared with the mean of 1.01 for men showed that they were more depressed $(F=6.06, p<0.05)$. There were no differences on any aspects of the work nor on stressful aspects of the job.

TABLE II-Distinguishing mean scores for subjects who were stressed and non-stressed at both the initial and follow up assessments

\begin{tabular}{lccccc}
\hline & \multicolumn{2}{c}{ Stressed $(\mathrm{n}=38)$} & & \multicolumn{2}{c}{ Non-stressed $(\mathrm{n}=63)$} \\
\cline { 2 - 3 } \cline { 5 - 6 } Attribute & Initial study & Follow up & & Initial study & Follow up \\
\cline { 3 - 3 } & & & & & \\
\cline { 6 - 7 } GHQ 12 & $17 \cdot 15$ & $16 \cdot 42$ & & $7 \cdot 87$ & $7 \cdot 85$ \\
Empathy & $4 \cdot 57^{\star}$ & $4 \cdot 62^{\star \star \star}$ & & $4 \cdot 29$ & $4 \cdot 20$ \\
Negative attributions & $4 \cdot 70$ & $4 \cdot 70^{\star}$ & & $4 \cdot 13$ & $3 \cdot 88$ \\
Self criticism & $4 \cdot 68$ & $5 \cdot 21^{\star \star \star}$ & & $3 \cdot 26$ & $3 \cdot 40$ \\
Disillusion & $3 \cdot 79^{\star}$ & $2 \cdot 97^{\star \star \star}$ & & $2 \cdot 89$ & $1 \cdot 75$ \\
\hline
\end{tabular}

${ }^{\star} \mathrm{p}<0.05 ;{ }^{\star \star} \mathrm{p}<0.001$. 


\section{Discussion}

The results show that this sample of house officers in their first postgraduate year suffered greater emotional strain than has been reported for other occupational groups ${ }^{16}$ and somewhat greater strain than they experienced as students. But given the change in their lives that their work created and the number of hours worked, the differences might have been even greater. Nevertheless, the prevalence rate of reporting levels that indicate psychiatric caseness is $50 \%$, which may be compared with $36 \%$ in women and $34 \%$ in men in a sample of executive civil servants. ${ }^{25}$ Such a large proportion will partly reflect short lived responses to the change in life circumstances as well as indications of morbidity. The depression scores, which are lower than those reported in North American studies, suggest that this is so. A conservative cutoff on the depression measure, however, showed that $28 \%$ of the sample had scores that indicated a depressive illness and 10 people reported thoughts of suicide, as did a fifth of subjects in the additional group of 25 . The high rate of response to the questionnaire and the significantly higher scores for both stress and depression reported by those initial non-responders suggest that the results are unlikely to reflect an overestimate of emotional distress. Given the lack of concentration, memory problems, and difficulty in decision making that are symptoms of depression (not to mention the general distress), $28 \%$ is unacceptably high.

The lack of a relation between drinking habits and stress levels may suggest that for some subjects alcohol is a successful way to maintain psychological well being in the short term. Nevertheless, nearly a fifth of the sample reported occasional or frequent bouts of heavy drinking, which is similar to findings in studies in the United States, ${ }^{11}$ and many had also reported such levels two years earlier. Though very few took drugs for anxiety, depression, or to help them sleep, a quarter of the sample took some medication for illness, which is a surprisingly high proportion in such a young group and may reflect the price paid by working long hours with inadequate sleep and a poor diet. Twelve used drugs for recreational purposes, and none reported frequent or regular use. With no information from a control group of similar age and status and no details of the drugs used it is impossible to say whether such numbers are high or low for Britain, though compared with the findings of McAuliffe $e t$ al the numbers are small. ${ }^{11}$ Nevertheless, serious consideration must be given to the drug and alcohol use reported.

Twenty two per cent of the sample were at caseness level on both occasions when they were tested, and this is in line with Depue and Monroe's argument that about a quarter of all populations are consistent in responding with symptoms to stress. ${ }^{26}$ Perhaps this suggests that more stringent selection would ensure that only the more resilient students take up medicine. But these young doctors had appreciably higher levels of empathy and were less likely to blame causes outside themselves for things that went wrong. Such attributes seem important in members of a caring profession, but they are likely to make a person more vulnerable to distress unless there is understanding and support in the working environment. Such support is an organisational matter, ${ }^{5}$ but in a profession where risks and failures are inevitable the allocation of "blame" should perhaps be covered during training.

Although there were no differences between men and women in the results of the first assessment, women doctors now report more symptoms of depression than men. ${ }^{27} 28$ These differences may grow as women are faced more and more with conflicts between family and career. Reducing such conflicts would also be an organisational matter, such as making training schedules more flexible, but because women hold few positions of power in the profession such change is likely to be slow. ${ }^{29}$

Junior medical staff in teaching hospitals seem to experience more stress than staff in non-teaching hospitals. This may be attributable to the greater size, larger staff, and more competitive atmosphere and reflect the doctors' higher expectations of themselves.

As in earlier studies, doctors in this study reported overwork as the most stressful aspect of their jobs. ${ }^{230}$ It has been suggested, however, that the constant emphasis on overload may mask more anxiety inducing fears. ${ }^{31}$ The negative effects the job has on personal life probably also reflects the high demands of the job occurring at a time when more permanent relationships usually begin. Demands, however, are not inevitably reflected in symptom levels since neither the number of hours worked nor the number of beds under a doctor's responsibility were related to stress levels, and it has been shown that demands can be counterbalanced by, for instance, participation in decision making. ${ }^{32}$ Moreover, the number of hours slept, the ability to adjust to sleep patterns, and ensuring an adequate diet seem more important, ${ }^{334}$ and while sleep loss is more difficult to change and may be the result rather than the cause of stress, a poor diet can be rectified. Talking to distressed relatives and serious treatment failures were also reported to be stressful, and training and support might usefully be directed at these areas.

There were highly significant correlations between levels of stress and perceptions of jobs. The more distressed the subjects were the more negatively they saw aspects of their roles, particularly when relating to consultants: they felt less able to discuss problems with senior colleagues and were less sure of what was expected of them. The causes may lie with either the house officer or the consultant, or both. Consultants could help-for example, by setting aside time to discuss problems, by setting achievable goals, and by giving both positive and negative feedback. ${ }^{8}$ If, however, it is necessary in order to remain unstressed for practitioners to continue to maintain low levels of empathy and to learn to make external attributions for their problems then it may be especially difficult for senior members of the profession to appreciate the emotional problems of junior staff.

The findings show that this group of junior house officers suffered high levels of stress but largely enjoyed their new jobs. At the same time a substantial proportion suffered high levels of emotional distress, some for at least two years, and depression. For many of these the symptoms may go away as they gain experience and can anticipate fewer constraints, but the first postgraduate year remains a risky one, especially for those with the characteristics discussed above.

This problem should undoubtedly be dealt with in medical school, ${ }^{35}$ but postgraduate training can also include support groups. ${ }^{7}$ Counselling helps to relieve occupational stress, ${ }^{36}$ and roughly half the house officers in this study thought it was necessary; this approach emphasises the individual rather than the environmental causes, and both should clearly be considered. Perhaps the difficulties of the job at all levels should be acknowledged, and physicians should try less to heal themselves and more to heal each other.

\section{References}

1 Murray RM. Psychiatric illness in male doctors and controls: an analysis of Scottish hospital inpatient data. Br $\mathcal{X}$ Psychiatry 1977;131:1-10.

2 Valko RJ, Clayton PJ. Depression in the internship. Diseases of the Nervous System 1975;36:26-9. 3 Anonymous. Alcohol-dependent doctors [Editorial]. Br Med $\mathcal{F}$ 1979;ii:351.

4 Vaillant GE, Brighton JR, McArthur M. Physicians' use of mood-altering drugs: a 20-year followup report. $N$ Engl f Med 1970;282:365-70.

5 MaCue JD. The distress of internship. N Engl f Med 1985;312:449-52.

6 Small GW. House officer stress syndrome. Psychosomatics 1981;22:860-9.

7 Ziegler JL, Kanas N, Struss WM, Bennet NE. A stress discussion group for medical interns. fMed Educ 1984;59:205-7.

8 Ford GV. Emotional distress in internship and residency: a questionnaire study. Psychiatric Medicine 1983;i:143-50.

9 Reuben DB. Depressive symptoms in medical house officers: effects of level of training and work rotation. Arch Intern Med 1985;145:286-8.

10 Firth J. Levels and source of stress in medical students. BrMed $\mathcal{F}$ 1986;292:1177-80.

11 McAuliffe WE, Rohman M, Wechsler H. Alcohol, substance use and other risk-factors of impairment in a sample of physicians-in-training. Adv Alcohol Subst Abuse 1984;4:67-87.

12 Vincent MO. Some sequelae of stress in physicians. Psychiatr f Univ Ottawa 1983;8:120-4.

13 AMA Council on Mental Health. The sick physician: impairment by psychiatric disorders, including alcoholism and drug dependence. $\mathcal{F} A M A$ 1973;223:684-7.

14 Seligman MEP. Depression and learned helplessness. In: Friedman RJ, Katz MM, eds. The psychology of depression: contemporary theory and research. Washington DC: Winston and Sons, 1974.

15 Goldberg DP. The detection of psychiatric illness by questionnaire. London: Oxford University Press, 1972. (Maudsley Monograph No 21.)

16 Banks MH, Clegg CW, Jackson PR, Kemp NJ, Stafford EM, Wall TD. The use of the general health questionnaire as an indicator of mental health in occupational settings. Fournal of Occupational Psychology 1980;53:187-94.

17 Derogatis LR, Lipman RS, Covi MD. SCL-90: an outpatient psychiatric rating scalepreliminary report. Psychopharmacol Bull 1973;9:13-20.

18 Mehrabian A, Epstein N. A measure of emotional empathy. F Pers 1972;40:525-43.

19 Brewin CR, Shapiro DA. Beyond locus of control: attribution of responsibility for positive and negative outcomes. Br f Psychol 1984;75:43-9. 
20 Blatt SJ, Quinlan DM, Chevron ES, McDonald C. Dependency and self-criticism: psychological dimensions of depression. F Consult Clin Psychol 1982;50:113-24.

21 Banks MH. Validation of the General Health Questionnaire in a young community sample. Psychol Med 1983;13:349-53.

22 Lloyd C, Gartell NK. A further assessment of medical student stress. I Med Educ 1983;58:964-7.

23 Gotlib IH. Depression and general psychopathology in university students. 7 Abnorm Psychol 1984;93:19-30.

24 Shapiro DA, Firth JA. Comparative outcomes of prescriptive versus exploratory psychotherapy: first findings from the Sheffield Psychotherapy Project. $B r f$ Psychiatry (in press)

25 Jenkins R. Sex differences in minor psychiatric morbidity. Psychol Med 1985;suppl 7.

26 Depue RA, Monroe SM. Conceptualization and measurement of human disorder if life stress research: the problem of chronic disturbance. Psychol Bull 1986;99:36-51.

27 Elliot DL, Girard DE. Gender and the emotional impact of internship. Fournal of the American Women's Association 1986;4:54-6.

28 Steppacher RC, Mausner JS. Suicide in male and female physicians. JAMA 1974;228:323-8.

29 Cartwright LK. Occupational stress in women physicians. In: Payne RL, Firth-Cozens J, eds.

Stress in the health professions. Chichester: Wiley (in press).
30 Werner ER, Korsch BM. Professionalization during pediatric internship. In: Shapiro EC, Lowenstein LM, eds. Development of attitudes in medicine. Cambridge: Ballenger, 1979.

31 Scheiber S. Stress in physicians. In: Payne RL, Firth-Cozens J, eds. Stress in the health professions. Chichester: Wiley (in press).

32 Karasek RA. Job demands, job decisions, latitude and mental strain: implications for job redesign. Administrative Science Quarterly 1979;24:258-308.

33 Hawkins MR, Vichick MD, Silsby HD, Kruzich DJ, Butler R. Sleep and nutritional deprivation and performance of house officers. I Med Educ 1985;60:530-5.

34 Friedman RC, Bigger JT, Kornfeld DS. The intern and sleep loss. N Engl f Med 1971;285:201-3. 35 Firth-Cozens J. The stresses of medical training. In: Payne RL, Firth-Cozens J, eds. Stress in the health professions. Chichester: Wiley (in press).

36 Sorenstein DB. Should physician training centers offer formal psychiatric assistance to house officers? A report on the major findings of a prototype program. Am f Psychiatry 1985;142: 1053-7.

(Accepted I May 1987)

\title{
How To Do It
}

\section{Broaden your mind about death and bereavement in certain ethnic groups in Britain}

\author{
JOHN BLACK
}

Immigration from the Indian subcontinent into Britain occurred mainly between 1950 and 1970, but with a few exceptions the health services have not attempted to understand or provide for their Asian patients. It is possible, though undesirable, to manage an illness without regard to a patient's ethnic origin, but to be ignorant of the religious beliefs and needs of a dying patient and his relatives is unforgivable. Much distress and offence can be caused by lack of understanding.

Though acknowledging the importance of the religions of nonAsian minority groups in Britain, I think that difficulties and misunderstandings are more likely with Asian patients whose cultures and beliefs differ considerably from those of "Western" religions. This article considers only the three main religions of the Indian subcontinent-Hinduism, Sikhism, and Islam. It should be appreciated that within Hinduism and Islam, and to a lesser extent Sikhism, there are wide variations in attitudes depending on the country of origin or adherence to a particular sect. A distinction should also be made between those who have come from east Africa and those who have come to Britain direct. In general, Asian men from east Africa are businessmen, shopkeepers, or members of the professions and have a more sophisticated approach than their counterparts from the Indian subcontinent, who have generally come from rural areas.

Hospitals, clinics, and practices in an area with a sizable population of a particular ethnic group or groups should make adequate provision for them..$^{1.3}$ Lists of religious or community leaders should be available, and, in areas where the numbers merit it, hospitals might consider the appointment of one or more of these leaders to a post equivalent to that of hospital chaplain. Ward staff should know that in some Asian cultures grief is shown more openly than is the custom in the West, and the provision of a side ward for the dying patient is a humane and sensible gesture.

The symbols of Christianity should be removed from chapels of

54 Ruskin Park House, Champion Hill, London SE5 8TQ JOHN BLACK, MD, FRCP, former consultant paediatrician
From How To Do It: 2, a new collection of useful advice on topics that doctors need to know about but won't find in the medical textbooks. To be published in October 1987, this is a companion volume to the popular How To Do It: 1 , also published by the $B M F$.

rest and crematoria when these are being used by non-Christians; sheets used to wrap the body should be plain. Hindus and Moslems but not Sikhs believe that non-members of their faiths should not touch the dead body, and if it is necessary for them to do so they should wear gloves. Jewellery and other insignia of possible religious significance should not be removed from the body without permission of the relatives.

\section{Hinduism}

The majority of the Hindus in Britain come from Gujarat, in western India, or from east Africa. Hinduism is a polytheistic religion, embracing a way of life and a social system. Hindus believe in a supreme being residing in each individual, and the ultimate goal is the release of the individual's soul from the cycle of birth, death, and rebirth to join the supreme being. A person's deeds in his past lives determine his status and good or ill fortune in his present life, whose quality, in turn, governs his future.

\section{RELIGIOUS ORGANISATION}

In Hinduism there is no supreme church authority and no hierarchy. Numerous gods are worshipped, each being the personification of a particular aspect of the supreme being. Most families worship at a shrine in their home and attend the temple (mandir) for communal worship. The temple is in the care of a priest (pandit, a teacher), generally a Brahmin (a member of the highest 